\title{
Estudos organizacionais, (des)colonialidade e estudos da dependência: as contribuições da Cepal
}

\author{
Estudios organizacionales, (de)colonialidad y estudios de la dependencia: las \\ contribuciones de CEPAL
}

Organization studies, (de)coloniality, and dependency studies: the contributions of CEPAL

Sergio Wanderley ${ }^{1}$

Fundação Getulio Vargas / Escola Brasileira de Administração Pública e de Empresas, Rio de Janeiro - RJ, Brasil

\begin{abstract}
Resumo
O objetivo deste artigo é (re)visitar o conceito de dependência como categoria de investigação da (e a partir da) América Latina, por meio de uma perspectiva histórica crítica descolonial, a fim de ampliar o espaço de debates em estudos organizacionais e promover alternativas à ordem neoliberal. Este ensaio terá como foco os estudos da dependência realizados pela Comissão Econômica para a América Latina e o Caribe (Cepal) durante a década de 1950 e o início dos anos 1960. A perspectiva descolonial é um constructo teórico de autores latino-americanos que se consideram herdeiros da longa tradição do pensamento social crítico da região, na qual a teoria da dependência está inserida. As propostas dos autores da dependência confrontaram as principais teorias ortodoxas do Norte produzidas à época. A partir do conceito de centro-periferia, da denúncia de assimetrias nas relações entre essas regiões, do reconhecimento da interdependência entre desenvolvimento e subdesenvolvimento, o conceito de dependência foi sendo (re)elaborado nas décadas de 1950 e 1960 por diversos autores latino-americanos como uma categoria de investigação da realidade da (e a partir da) região. Essas investigações tinham por objetivo não somente elaborar constructos teóricos, mas, também, transformar a realidade por meio da criação de diversas organizações e instituições que deveriam servir ao propósito de superar o subdesenvolvimento. A denúncia da historicidade da situação de subdesenvolvimento desnudou o caráter de neutralidade do economicismo das teorias produzidas no Norte e promoveu um encontro teórico entre economia e política que muito tem a contribuir com a área dos estudos organizacionais.
\end{abstract}

Palavras-chave: Colonialidade epistêmica. Descolonialidade. Dependência. Desenvolvimento.

\section{Resumen}

Este artículo objetiva (re)visitar el concepto de dependencia como una categoría de investigación de la (y desde la) América Latina, a través de una perspectiva histórica crítica descolonial, con el fin de ampliar el espacio de debates en estudios organizacionales y promover alternativas al orden neoliberal. Este ensayo se centrará en los estudios de la dependencia realizados por la Comisión Económica para América Latina y el Caribe (CEPAL) durante la década de 1950 y principios de los años 1960. La perspectiva decolonial es un constructo teórico de autores latinoamericanos que se consideran herederos de la larga tradición del pensamiento social crítico de la región, en la que se inserta la teoría de la dependencia. Las propuestas de los autores de la dependencia confrontan las principales teorías ortodoxas del Norte producidas en aquella época. Desde el concepto de centro-periferia, de la queja por las asimetrías en las relaciones entre estas regiones, del reconocimiento de la interdependencia entre desarrollo y subdesarrollo, el concepto de

Artigo submetido em 31 de janeiro de 2014 e aceito para publicação em 29 de setembro de 2014

DOI: http://dx.doi.org/10.1590/1679-395115852

${ }^{1}$ Doutor e Mestre em Administração pela Fundação Getulio Vargas/EBAPE; Professor da Escola Brasileira de Administração Pública e de Empresas da Fundação Getulio Vargas. Endereço: FGV/EBAPE - Escola Brasileira de Administração Pública e de Empresas, Praia de Botafogo, 190 - 4ํㅜㄴ 5a andares - Botafogo, CEP 22250-900, Rio de Janeiro - RJ, Brasil. E-mail: sergio.wanderley@fgv.br 
dependencia ha sido (re)elaborado en los años 1950 y 1960 por varios autores latinoamericanos como una categoría de investigación de la realidad de la (y desde la) región. Estas investigaciones tenían como objetivo no sólo elaborar constructos teóricos, sino también transformar la realidad a través de la creación de diversas organizaciones e instituciones que deberían servir para el propósito de superar el subdesarrollo. La queja de la historicidad de la situación de desarrollo ha desnudado el carácter de neutralidad del economicismo de las teorías producidas en el Norte y ha promovido un encuentro teórico entre economía y política que tiene mucho que aportar en el área de los estudios organizacionales.

Palabras clave: Colonialidad epistémica. Decolonialidad. Dependencia. Desarrollo.

\section{Abstract}

This article aims to (re)visit the concept of dependency as a category of investigation of (and from) Latin America, by means of a decolonial critical historical perspective, in order to increase space for debates on organization studies and promote alternatives to the neoliberal order. This essay will focus on dependency studies conducted by the Economic Commission for Latin America and the Caribbean (ECLAC) during the 1950s and early 1960s. The decolonial perspective is a theoretical construction by Latin American authors who deem themselves as heirs of the long-standing tradition of critical social thought in the region, where the dependency theory is situated. The proposals of dependency authors challenged the main orthodox theories from the North produced at that time. Through the concept of centerperiphery, the denunciation of asymmetries in the relations between these regions, and the recognition of interdependency between development and underdevelopment, the concept of dependency was (re)elaborated along the 1950s and 1960s by many Latin American authors as a category of investigation of the reality of (and from) the region. These investigations aimed not only to formulate theoretical constructions, but also to transform reality by creating various organizations and institutions that might serve the purpose of overcoming underdevelopment. Denunciating the historicity of the underdevelopment situation has unveiled the neutrality nature of the economism of theories produced in the North and promoted a theoretical encounter between economics and politics that has much to contribute to the field of organization studies.

Keywords: Epistemic Coloniality. Decoloniality. Dependency. Development.

\section{Introdução}

A preponderância do conhecimento anglo-saxão na literatura dos estudos organizacionais (EOR) produzida na América Latina tem sido denunciada por diversos autores da região (RODRIGUES e CARRIERI, 2001; SARAIVA e CARRIERI, 2009), que também alertam para o fato de que autores latino-americanos tendem a assimilar acriticamente as teorias vindas do Norte, sejam elas mainstream ou críticas, em um processo de autoimposição da colonialidade (IBARRA-COLADO, 2008). Nessa mesma linha, Waiandt (2009), que investigou a história do currículo de EOR nas principais escolas nacionais, concluiu que seu conteúdo é predominantemente estrangeiro.

A falta de representatividade da América Latina, tanto na publicação nos principais periódicos em EOR como em seus quadros editoriais, foi designada por autores do Norte como uma forma de neoimperialismo (MURPHY e ZHU, 2012). Essa autoimposição da colonialidade também se torna aparente quando verificamos o ranque dos periódicos para autores brasileiros. Estes se veem quase que obrigados a publicar em inglês para obter maiores pontuações, o que deixa a dúvida: o "conhecimento em gestão e estudos organizacionais pode falar português?" (ROSA e ALVES, 2011).

Portanto, faz-se necessário o engajamento com uma perspectiva descolonial, a fim de trazer à tona conhecimentos e realidades produzidas na (e a partir da) América Latina que foram encobertos pela colonialidade epistêmica imposta pelo conhecimento hegemônico do Norte (DUSSEL, 1993). Por colonialidade epistêmica entendemos a imposição de conhecimentos produzidos a partir de outra realidade e que se sobrepõe às práticas e conhecimentos locais, terminando por provocar a subalternização destes (IBARRA-COLADO, 2006; MIGNOLO, 2011). Dessa maneira, o objetivo deste artigo é (re)visitar o 
conceito de dependência como categoria de investigação da (e a partir da) América Latina, a fim de ampliar $\mathrm{o}$ espaço de debates em EOR e promover alternativas à ordem neoliberal.

Este ensaio terá como foco os estudos produzidos pela Comissão Econômica para a América Latina e o Caribe (Cepal) durante a década de 1950 e o princípio dos anos 1960. A partir desse período, a Cepal passa por críticas internas e externas que promoverão a ampliação das teorizações em torno do conceito da dependência, gerando, assim, diferentes correntes de pensamento. Essas diferentes teorizações aprofundam as raízes latino-americanas dos estudos da dependência, incluindo-se aí sua revisão a partir de conceitos marxistas, apropriados à realidade local, o que ficou conhecido como a teoria marxista da dependência (TMD) (BEIGEL, 2010). Recentemente, autores em EOR têm procurado resgatar os conceitos da TMD, seja associando-os aos conceitos da perspectiva descolonial (MISOCZKY, 2011), seja por meio do resgate do pensamento social crítico brasileiro (MISOCZKY e FLORES, 2009). Portanto, este ensaio procura se juntar a esse movimento e almeja deixar como contribuição o reconhecimento das diferentes correntes de estudos da dependência e, em particular, as contribuições dos estudos da Cepal para os EOR. É necessário reconhecer, todavia, que as formulações da Cepal são anteriores às diferentes (re)formulações em diferentes tons marxistas da teoria da dependência e que servem de base a elas. Por exemplo, o artigo "The development of underdevelopment", de Frank (1966), não teria sido possível sem o livro Desenvolvimento e subdesenvolvimento, de Furtado (1961) - que saiu na versão em inglês em 1964 - e construções anteriores da Cepal. As formulações da Cepal propunham abordagem teórica e prática diferente daquela recebida do Norte, contudo, sem romper com o capitalismo; por outro lado, a TMD sugeria que a única solução para os países subdesenvolvidos saírem de sua condição seria por meio de uma revolução socialista e rompimento com o capitalismo.

O projeto da modernidade/colonialidade/descolonialidade (MCD) é uma construção teórica de autores latinoamericanos que se consideram herdeiros da longa tradição do pensamento social crítico da região, na qual a teoria da dependência está inserida (ESCOBAR, 2007; BALLESTRIN, 2013). "Colonialidade" é um neologismo criado para designar a dominação de poder (QUIJANO, 2000), do ser e do conhecimento (MIGNOLO, 2011), que persiste mesmo após a eliminação da dominação política do colonialismo e que impõe a racionalidade da modernidade sob uma perspectiva meramente euroamericana (MIGNOLO, 2011). Os autores da MCD partem da premissa de que modernidade e colonialidade iniciam-se simultaneamente, com a descoberta da América pelos europeus em 1492 (DUSSEL, 1993) e, desde então, modernidade e colonialidade são partes inseparáveis do mesmo fenômeno. A colonialidade é o lado negro - e negado - da modernidade eurocêntrica (MIGNOLO, 2011). O compromisso histórico com a pluriversalidade do conhecimento, em oposição ao eurocentrismo universal, é uma contribuição política e teórica importante da América Latina ao enfrentar o desafio de promover práticas locais e estudos em gestão e organizações de forma que não sejam classificados como "disfuncionais em relação a uma forma ideal e eficaz de práticas modernas em gestão do norte" (ALCADIPANI, KHAN, GANTMAN et al., 2012, p. 134). A teoria da dependência (TD) - como foi batizada pelo Norte - vem a ser um bom exemplo de contribuição teórica da América Latina que foi subalternizada pelas forças dominantes e que poderia ajudar a ampliar o espaço de debates em EOR, escapando da lógica única neoliberal.

As propostas dos autores da dependência confrontaram as principais teorias ortodoxas do Norte produzidas à época. A partir do conceito de centro-periferia, da denúncia de assimetrias nas relações entre estas regiões (PREBISCH, 1949), do reconhecimento da interdependência entre desenvolvimento e subdesenvolvimento e da consequente negação de que representariam diferentes etapas de um mesmo fenômeno (FURTADO, 1961) - o conceito de dependência foi sendo (re)elaborado nas décadas de 1950 e 1960, por diversos autores latino-americanos como uma categoria de investigação da realidade da (e a partir da) região. Essas investigações tinham por objetivo não somente elaborar construções teóricas, mas, sim, a transformação da realidade por meio da criação de diversas organizações e instituições que deveriam servir ao propósito de superar o subdesenvolvimento. A denúncia da historicidade da situação de subdesenvolvimento desnudou o caráter de neutralidade do economicismo das teorias produzidas no Norte e promoveu um encontro teórico entre economia e política (BEIGEL, 2006) que muito tem a contribuir com a área de EOR. 
$\mathrm{Na}$ próxima seção apresentamos nossa proposta para uma perspectiva histórica crítica descolonial. Em seguida, apresentamos a análise do contexto da construção do conhecimento da Cepal. Então, discutimos as diferentes correntes que compõem os estudos da dependência e quais desdobramentos levaram à (re)formulação da teoria da dependência sob uma perspectiva marxista. Na última parte, tecemos nossas considerações finais.

\section{Descolonialidade como uma Perspectiva Histórica Crítica a Partir da América Latina}

O projeto modernidade/colonialidade/descolonialidade se considera herdeiro das principais teorizações críticas da América Latina, como a teoria da dependência e a teologia da libertação (ESCOBAR, 2007; BALLESTRIN, 2013), e seu principal autor é o filósofo e semiólogo argentino Walter Mignolo. Mignolo se baseia, principalmente, nos conceitos desenvolvidos por outro filósofo argentino, Enrique Dussel (1993), e pelo sociólogo peruano Anibal Quijano (2000). Para esses autores, a colonialidade persiste por um longo período, mesmo após a eliminação da dominação política do colonialismo, e que impõe a racionalidade da modernidade de uma perspectiva racista e meramente europeia. Como consequência, conhecimento e realidades locais são encobertos, e, assim, ignorados, pela lógica única da modernidade europeia e, portanto, necessitamos da descolonialidade para libertá-los. Como a modernidade atingiu todas as sociedades do mundo, segundo Mignolo (2011), precisamos partir para as margens do sistema, a fim de criar alternativas para a modernidade. Assim, não há uma parte externa à modernidade; consequentemente, "o pensamento da margem é a epistemologia da exterioridade, isto é, do externo gerado a partir do interno" (MIGNOLO e TLOSTANOVA, 2006, p. 206).

Um conceito central para a promoção de teorização a partir da margem é o lócus de enunciação (Mignolo, 2011). Para Mignolo (2011), devemos mobilizar a geopolítica do conhecimento, a fim de mudar o foco daquilo que é enunciado para a enunciação; para tanto, devemos nos perguntar "quem e quando, porque e onde o conhecimento é gerado" (MIGNOLO, 2009, p. 4). É por meio do pensamento a partir das margens do Sul que podemos descolonizar histórias e teorizações locais como os estudos da dependência, que foram subalternizadas pela colonialidade epistêmica (IBARRA-COLADO, 2006) imposta por uma perspectiva colonialista de modernidade.

Para Mignolo (2000; 2011), essas margens são formadas pelo encontro entre modernidade e colonialidade, e é aí que surge a "diferença colonial". Então, é imprescindível que se promova um "pensamento crítico das margens", para que se possa dar voz às diferenças coloniais e promover a geração de pluriversalidade, não universalidade. Portanto, o objetivo é atingir um mundo multipolar informado por conhecimentos tanto do Norte como do Sul, ao invés de um mundo unipolar informado somente pela modernidade eurocêntrica (MIGNOLO e TLOSTANOVA, 2006). Em nossa opinião, o conhecimento produzido pelos autores da dependência foi produzido a partir dessa "diferença colonial", representando o "externo gerado a partir do interno" (MIGNOLO e TLOSTANOVA, 2006). Isso se caracteriza, em particular, no caso da Cepal, que é uma agência da Organização das Nações Unidas (ONU) e, como tal, deve seguir suas regras que, claramente, são formadas a partir do lócus de enunciação das teorias de modernização do Norte. Uma evidência desse fato foi a reelaboração que Prebisch (1949) teve de fazer no "Manifesto de Havana", para que este se enquadrasse como um documento oficial da ONU (BIANCHI, 2002). Prebisch (1949) também se referiu a mensagens recebidas de Washington que recriminariam o posicionamento da Cepal sobre alguns temas (DOSMAN, 2011).

A partir de uma perspectiva descolonial, concordamos com a afirmação de que "os estudos organizacionais e em gestão são notoriamente a-históricos" (ROWLINSON, JACQUES e BOOTH, 2009, p. 287), e consideramos que os discursos e práticas de gestão são fenômenos históricos, sociais e geopolíticos (BOOTH e ROWLINSON, 2006), e que o conhecimento contemporâneo não deve ser naturalizado, mas, sim, considerado resultado de práticas que poderiam ter ocorrido de maneira distinta (JACQUES, 2006). 
Estamos de acordo com os autores do Norte, que pregam uma "virada histórica" (CLARK e ROWLINSON, 2004) em EOR, a fim de superarmos a a-historicidade da área e para a problematização de conceitos naturalizados (CLARK e ROWLINSON, 2004; BOOTH e ROWLINSON, 2006; ROWLINSON, JACQUES e BOOTH, 2009). Todavia, a partir do lócus de enunciação da América Latina, entendemos que uma "virada geográfica" também se faz necessária, a fim de que possamos questionar a continuidade da hegemonia do conhecimento anglo-saxão. Hegemonia esta que também está presente no que diz respeito à produção da crítica ao eurocentrismo, o que concorre para reforçar a lógica da colonialidade, ao invés de atenuá-la. Ao propor os conceitos de centro-periferia (PREBISCH, 1949), e ressaltar as assimetrias nas relações entre essas regiões, os autores da dependência procuraram apoiar suas teorizações em outro eixo geográfico e, a partir daí, buscar a construção de organizações e instituições para promover o desenvolvimento hacía adentro (PREBISCH, 1949).

Portanto, em face da ausência de uma perspectiva crítica das margens do Sul que assuma a colonialidade como uma premissa básica da modernidade (MIGNOLO, 2000; 2011) e o fato de autores latino-americanos tenderem a assimilar acriticamente as teorias vindas do Norte, sejam elas mainstream ou críticas, em um processo de autoimposição de colonialidade (IBARRA-COLADO, 2008), leva este artigo a abraçar uma perspectiva descolonial. Aqui, sugerimos que a abordagem descolonial pode ajudar a ampliar o espaço de diálogo em EOR e atenuar a colonialidade epistêmica manifesta na importação de conhecimento estrangeiro (RODRIGUES e CARRIERI, 2001; SARAIVA e CARRIERI, 2009), e a fim de não ficarmos reduzidos à situação em que "discutir estudos organizacionais na América Latina é discutir a importação, tradução e repetição de conhecimento produzido no mundo anglo-saxão e é, consequentemente, a história de um discurso falso" (IBARRA-COLADO, 2006, p. 465).

Não está exatamente definido na literatura como realizar uma análise histórica crítica descolonial, a não ser pela preocupação com a especificação do lócus de enunciação (MIGNOLO, 2011). Entretanto, está claro que, a decisão do pesquisador por analisar alguns documentos e deixar de levar outros em consideração, por si, transforma o pesquisador em parte ativa da reconstrução do passado (COOKE, 1999). Portanto, assumimos uma posição de rejeitar a "arrogância do ponto zero", ou seja, rejeitamos a perspectiva eurocêntrica de produção do conhecimento de neutralidade do pesquisador, bem como a possibilidade de que este possa proceder a uma análise absolutamente isenta do objeto (CASTRO-GÓMEZ, 2007). A análise deste artigo parte de dois pressupostos: "1) conhecimentos são coproduzidos no tempo e espaço pelo contexto e por indivíduos; 2) indivíduos e contextos são coproduzidos por conhecimentos no tempo e espaço" (WANDERLEY e FARIA, 2012, p. 225).

\section{CEPAL, Dependência e Guerra Fria}

A questão mais importante, a partir de uma perspectiva descolonial, é entender porque o status disciplinador do conhecimento em EOR produzido nos EUA tornou-se aceito, tanto no Norte como no Sul, como "verdades objetivas e universais para organizar relações de trabalho" (JACQUES, 1996, p. xiii). Pesquisas em EOR produzidas no Norte veem discutindo a importância da Guerra Fria na produção e disseminação de conhecimento no pós-Segunda Guerra Mundial, mas vêm mantendo como foco questões internas dos EUA (COOKE, 1999; COOKE, MILLS e KELLEY, 2005; GRANT e MILLS, 2006; KELLEY, MILLS e COOKE, 2006; LANDAU, 2006; MCLAREN e MILLS, 2008; MCLAREN, 2011), ao passo que a repercussão da Guerra Fria na exportação desse mesmo conhecimento para a América Latina tem sido pouco estudada (como exceção, ver ALCADIPANI e BERTERO, 2012; BARROS e CARRIERI, 2013).

Algumas dessas pesquisas produzidas no Norte deixam claro a influência que a grande narrativa da Guerra Fria teve na produção e disseminação de conhecimento em EOR. Grant e Mills (2006, p. 202) apontaram que a Academy of Management teve um importante papel na disseminação do conteúdo da Guerra Fria, "que se traduziu numa filosofia da administração que influenciou as características da organização por várias décadas". O "gestor ideal" que foi gerado no contexto da Guerra Fria caracterizou-se por ser "um homem 
educado que exercia efetivamente a autoridade e que aceitava sua responsabilidade social" (MCLAREN e MILLS, 2008, p. 386). Além disso, o impacto do contexto da Guerra Fria fez com que "os gestores assumissem o papel de classe dirigente através de uma combinação de uma ideologia capitalista anticomunista e de ordenação, e de ideologias administrativas disciplinadoras" (MCLAREN, 2011, p. 419).

Sob uma perspectiva descolonial e a partir do lócus de enunciação da América Latina, é preciso reconhecer quais consequências teve a Guerra Fria na produção de conhecimento local. Um grande desafio enfrentado pelos acadêmicos, tanto do Sul como, principalmente, do Norte, é estar ciente de que a Guerra Fria "representou tanto uma realidade empírica quanto um quadro ideológico" (SPECTOR, 2006, p. 276) e é preciso ter em conta que isso ainda acontece. A Guerra Fria foi corretamente apresentada como "uma guerra entre versões de modernização" (COOKE, MILLS e KELLEY, 2005, p. 10). Além disso, veremos que nessa "guerra" entre as duas versões de modernização produzidas pelo primeiro e segundo mundos, os estudos da dependência, por não se alinharem com nenhuma das duas, acabaram por ser subalternizados.

É a partir da divisão do mundo entre os dois impérios, os EUA e a União Soviética, que surge a designação de "Terceiro Mundo" para o "resto", e sobre o qual seria imposto um discurso de desenvolvimento com o objetivo de ajudar os "subdesenvolvidos" (ESCOBAR, 1988). A criação desses dois termos artificiais Terceiro Mundo e subdesenvolvimento (ESCOBAR, 1988) - marca o lançamento da grande estratégia de "desenvolva-se ou eu atiro" (GROSFÓGUEL, 2011). "Desenvolvimento e management são, de uma maneira geral, projetos de modernização" (DAR e COOKE, 2008, p. 8). Nada deveria estar no caminho da imposição ao mundo do complexo político-comercial-militar dos EUA (WESTWOOD e JACK, 2008). Foi sob essas condições que "o desenvolvimento funcionou como um mecanismo todo poderoso para a produção e management do Terceiro Mundo no período após a $2^{a}$ Guerra Mundial" (ESCOBAR, 1992, p. 24). A "exportação" do desenvolvimento made in USA foi uma forma de barrar o avanço do comunismo (KELLEY, MILLS e COOKE, 2006), ao passo que a adoção das práticas em EOR era vista no Brasil como equivalente ao desenvolvimento (ALCADIPANI e BERTERO, 2012).

Percebemos que a forma como as fundações - Ford, Carnegie e Rockfeller - e as instituições norteamericanas promoveram a expansão do American one best way para a Europa e Ásia é similar, e simultânea, à forma como esse mesmo conhecimento foi transmitido para a América Latina, apesar de haver poucos estudos que analisam esse processo e que focam a implantação de escolas de administração no Brasil (FISCHER, 1984; ALCADIPANI e CALDAS, 2012; BARROS e CARRIERI, 2013). Diante desse contexto, seria natural esperar que a Guerra Fria tenha no mínimo restringido as agendas de pesquisa dos acadêmicos do Sul e constrangido os conhecimentos que seriam exportados e aqueles que poderiam ser reconhecidos (FARIA e GUEDES, 2007). Por exemplo, podemos citar a restrição que sofreu a teorização da Cepal que deixou explícito um posicionamento ideológico e ocupou um espaço que não se alinhava com nenhum dos dois lados hegemônicos no pós-Segunda Guerra Mundial, abrindo, assim, caminho para um discurso terceiro-mundista, mas que ainda se mantinha dentro de um âmbito econômico.

A exportação do desenvolvimento made in USA e o correspondente conhecimento em GEO que o acompanhou, tem um marco importante no discurso de posse do segundo mandato do presidente americano, Harry Truman (1949). Nesse discurso, ele lançou o programa Ponto IV, que se tornou um importante instrumento para o financiamento da expansão do conhecimento em EOR dos EUA para o Terceiro Mundo, como uma forma de bloquear a expansão do comunismo (IBARRA-COLADO, 2006). O programa Ponto IV afirma que "sua pobreza [áreas subdesenvolvidas] é um obstáculo e uma ameaça tanto para eles mesmos quanto para as áreas mais prósperas" (TRUMAN, 1949, p. 3). É nesse contexto que é criada, com um mandato provisório de três anos, em 1948 em Santiago do Chile, a Cepal, como uma agência regional da ONU para propor soluções econômicas para o desenvolvimento da região. Na verdade, os latino-americanos e, principalmente, o Brasil, que enviara tropas à Segunda Guerra Mundial, ansiavam por algo como o Plano Marshall, com o qual a Europa havia sido contemplada (DOSMAN, 2011). Todavia, os governos latinoamericanos tiveram de contentar-se com um pequeno grupo de economistas aos quais se juntou Celso Furtado, que foi para a Cepal imediatamente após obter seu grau de Ph.D pela Universidade Sorbonne, em 1948. Nesse cenário, era de esperar que a Cepal se tornasse mera reprodutora das teorias de modernização insufladas pelo centro. Santiago tornou-se o lócus a partir do qual os estudos da dependência se 
desenvolveriam: "a passagem através do Chile foi um fator determinante para a emergência da teoria da dependência" (BEIGEL, 2010, p. 143).

Foi na $2^{\mathrm{a}}$ conferência anual da Cepal, em Cuba, em 1949, que Raúl Prebisch, que então atuava como consultor e que se tornaria secretário-geral no ano seguinte, apresentou o relatório que depois ficou conhecido como o "Manifesto de Havana". Esse manifesto apresentou os conceitos de centro-periferia na economia global e levantou uma proposta de desenvolvimento apoiado pelo Estado que se opunha à teoria ortodoxa. Os especialistas, tanto dos países desenvolvidos como dos países em desenvolvimento, concordaram que "um novo debate havia sido lançado" (DOSMAN, 2011, p. 285). Essas ideias e as teorizações correspondentes foram vistas por instituições ortodoxas como uma ameaça à disseminação para a América Latina das teorias, dos conhecimentos e das instituições estadunidenses (FURTADO, 1998). O manifesto desafiava o "falso senso de universalismo existente na teoria usada nos países desenvolvidos" (PREBISCH, 1949, p. 17). Furtado compreendeu a força dessas propostas teóricas e traduziu-as para o português, conseguindo publicá-las no mesmo ano na Revista Brasileira de Economia da FGV, antes mesmo de tornarem-se um documento oficial da ONU (FURTADO, 1998).

As ideias formuladas pela Cepal foram, em grande parte, bem recebidas pelos Estados desenvolvimentistas que governavam a região (BIANCHI, 2002). Nosso entendimento de que a Cepal se encontrava em uma posição de "diferença colonial" (MIGNOLO, 2011) e gerando conhecimento a partir daí, ou seja, "do externo gerado a partir do interno" (MIGNOLO e TLOSTANOVA, 2006), pode ser exemplificado quando comparamos o Manifesto de Havana com o correspondente documento oficial que depois foi produzido para a ONU. Esse documento tinha um tom bem mais brando que o apresentado em Havana, que tinha por objetivo angariar o apoio dos representantes dos governos latino-americanos que assistiram à apresentação de Prebisch (BIANCHI, 2002). Ainda que o documento oficial tenha sido produzido em tom mais brando, Prebisch afirmou que recebeu da sede da ONU um memorando informando que a Cepal não tinha instruções para tratar as questões apresentadas em Havana como "desenvolvimento, industrialização, termos de troca e outros" (POLLOCK, KERNER e LOVE, 2001, p. 11). Ou seja, "pensando a partir das margens do sul" (MIGNOLO, 2007), o interno mandou avisar ao externo que deveria se conter. O fato é que "o radicalismo crítico da Cepal sofreu restrições por sua posição politico-institucional" (CARDOSO, 1977b). Na verdade, Prebisch foi hábil ao apresentar um manifesto que "consolidava uma série de visões e políticas que já faziam parte do meio intelectual dominante na América Latina" (VERNENGO, 2006, p. 556), e que discutiam alternativas para o desenvolvimento, propiciando assim embasamento teórico para as práticas que emergiam na região.

A partir da conferência de Havana, os países da América Latina passaram a contar com a Cepal para diagnósticos e formulação de políticas de desenvolvimento que, eventualmente, seriam implementadas durante os anos 1950 e 1960, que demarcaram o auge da atuação da Cepal na região (LOVE, 2005). Por conseguinte, o programa de "industrialização por substituição de importações" (ISI) foi implementado por diversos governos da região (BIELSCHOWSKY, 1987). No Brasil, a administração de dois presidentes Getúlio Vargas (1950-1954) e Juscelino Kubitschek (JK) (1956-1960) - ficaram marcadas por ter a Cepal como um importante apoio para a formulação de políticas (ver, por exemplo, KUBITSCHEK, 1955). Após a criação do Banco Nacional de Desenvolvimento Econômico (BNDE) em 1952, Furtado liderou o Grupo Misto Cepal-BNDE, que deveria definir os projetos de infraestrutura que seriam financiados pelo governo. $\mathrm{O}$ trabalho desenvolvido por esse grupo tornou-se uma das bases do programa de desenvolvimento do governo JK, que ficou conhecido como "Plano de Metas" (FURTADO, 2009), e no qual o Estado liderou a iniciativa privada no processo de desenvolvimento.

O conhecimento produzido pela Cepal influenciou, em particular no Brasil, não somente a criação e as práticas de empresas, órgãos e instituições públicas e/ou privadas, mas adentrou instituições de ensino que podemos afirmar que tratavam também de práticas organizacionais, sejam elas públicas ou privadas. Como exemplo dessas organizações, podemos citar, no Brasil, o BNDE. Apesar de sua criação, aparentemente, não ter tido influência direta da Cepal, a constituição do Grupo Misto Cepal-BNDE sob a liderança de Furtado, em 1953, um ano após a criação do banco, teve forte marca na formação de seus quadros e direcionamento de políticas (BNDE, 1956). Como sequência a esse Grupo Misto, o BNDE solicitou à Cepal que ministrasse 
no Rio de Janeiro cursos para a formação de quadros de diversos órgãos das diferentes esferas de governo (BNDE, 1957). Nesses cursos de "treinamento em problemas de desenvolvimento econômico", em nível de pós-graduação, foram formados mais de mil servidores entre 1956 e 1967 (SANTANA, 1990). Esses cursos foram apoiados pela Campanha de Aperfeiçoamento de Pessoal de Ensino Superior (Capes) e também contaram com o apoio do Instituto Superior de Estudos Brasileiros (Iseb) (CAPES, 1956). Podemos até afirmar que esses cursos representam os primeiros em nível de pós-graduação para administradores públicos. Esse curso teve uma edição especial no Recife, em 1959, com o intuito específico de formar quadros para a recém-criada Superintendência de Desenvolvimento do Nordeste (Sudene) (CAPES, 1960). A Sudene teve Furtado como primeiro superintendente e organizador, e sua estruturação ocorreu de acordo com os preceitos formulados pela Cepal (ARQUIVOS CELSO FURTADO, 2009). O próprio Iseb, que se encarregava de formar e influenciar a elite dirigente do país (ABREU, 2005), também sofreu a influência da Cepal (SODRÉ, 1978). Cabe relembrar que será no Iseb que Guerreiro Ramos (1958, p. 20) publica a "Redução sociológica", que se encontra impregnada de teorizações sobre o desenvolvimento - questão central para a Cepal e o momento que vivia o país - e, segundo o autor, "O imperativo do desenvolvimento suscitou a consciência crítica".

A influência da Cepal também se fez sentir na construção e atuação de organizações nos demais países da América Latina. Por exemplo, no Chile, a atuação da Corporación de Fomento, órgão estatal de apoio ao desenvolvimento, teve o suporte da Cepal, bem como o banco de desenvolvimento criado no México (FURTADO, 1998). Contudo, a ordem neoliberal imposta ao mundo a partir dos anos 1980 acabou por extinguir essas duas organizações, enquanto que no Brasil as marcas institucionais de atuação da Cepal permanecem claras até hoje, não somente nas organizações criadas nos anos 1950, mas, também, em instituições acadêmicas, como a Universidade Federal do Rio de Janeiro (UFRJ) e a Universidade Estadual de Campinas (Unicamp) (VERNENGO, 2006).

As ideias-força da Cepal (BIELSCHOWSKY, 1998) desafiavam a teoria ortodoxa da modernização de três maneiras básicas: 1) propunham uma teorização específica para a condição de subdesenvolvimento e rejeitavam que este fosse mero estágio no caminho para o desenvolvimento; 2) rejeitava a teoria das vantagens comparativas do comércio internacional (BIELSCHOWSKY, 1998); 3) ao introduzir o conceito de centro-periferia, rejeitava, também, a condição de que o país fosse a unidade de análise e tinha o sistema global e suas várias formas de interação como premissa básica de análise (VALENZUELA e VALENZUELA, 1978). Esse corpo de conhecimento gerado inicialmente pela Cepal tornou-se conhecido no conjunto por "estruturalismo", também pelo fato de destacar que a inflação crônica da região devia-se mais a fatores estruturais que monetários, em mais uma confrontação com a teoria ortodoxa (BIELSCHOWSKY, 1987).

Além disso, a Cepal desenvolveu, e Furtado foi um de seus principais artífices (BIELSCHOWSKY, 1998, p. 21), o original método histórico-estrutural, que é "essencialmente um enfoque orientado pela busca de relações diacrônicas, históricas e comparativas [...] profundamente atento para o comportamento dos agentes sociais e da trajetória das instituições" e que ressalta as imperfeições de mercado geradas por essas interelações ao longo de construções históricas específicas. Em outras palavras, a teorização da Cepal não aceitava o mito ortodoxo da "mão invisível", muito menos da "mão visível" (CHANDLER, 1977), que proporcionaria o equilíbrio automático do mercado. Muito pelo contrário, a premissa era de que em situações de subdesenvolvimento a tendência seria um desequilíbrio crônico e, assim, a atuação do Estado por meio do planejamento e da indução dos agentes econômicos fazia-se necessária em busca do desenvolvimento (BIELSCHOWSKY, 1998).

Um exemplo de colonialidade epistêmica (IBARRA-COLADO, 2006) foi a imediata reação à propagação das novas ideias lançadas pela Cepal: o programa Ponto IV financiou, no início dos anos 1950, uma série de palestras no Rio de Janeiro - na época, tida por muitos como a capital intelectual da América Latina. Foram enviados para o Brasil economistas ortodoxos, como Jacob Viner, para ministrar palestras no recém-criado Instituto Brasileiro de Economia (Ibre) da Fundação Getulio Vargas (FGV) e na Universidade do Brasil (FURTADO, 1998). Para Furtado, isso ocorreu com o objetivo de "restaurar a boa doutrina [...] para limpar o ambiente intelectual dos miasmas cepalinos" (FURTADO, 1998, p. 19). A colonialidade manifestou-se 
também no fato de que os EUA tentaram extinguir a Cepal, em 1951, ao final de seu mandato provisório, ao propor sua fusão com a Organização dos Estados Americanos (OEA). A Cepal foi salva pela intervenção do presidente brasileiro Getúlio Vargas (FURTADO, 1974).

A proposição de que desenvolvimento e subdesenvolvimento são processos simultâneos, isto é, "são as duas faces da evolução histórica do sistema capitalista" (SUNKEL, 1972, p. 520) era a base do conhecimento defendido pela Cepal e por Furtado (1961), e tornou-se um dos pilares sobre os quais a teorização da simultaneidade de modernidade e colonialidade foi construída (ESCOBAR, 2007; MIGNOLO, 2011). Esse conceito teórico formulado originalmente pela Cepal a partir do Sul ia de encontro à teoria ortodoxa universal, que versava que o subdesenvolvimento era apenas uma fase que seria superada no caminho para o desenvolvimento (ROSTOW, 1960). De acordo com essa teoria de modernização, países subdesenvolvidos deveriam seguir os métodos ortodoxos de desenvolvimento e comprometer-se com o "bom conhecimento" (ROSTOW, 1960). Esse modelo estadunidense foi massivamente exportado para a América Latina, levando, portanto, a uma imposição sobre o conhecimento produzido na região. O próprio Rostow tornou-se consultor do governo militar no Brasil após o golpe de 1964 (SANTOS, 2000), mesmo momento em que Furtado é exilado, enquanto que no Chile, sede da Cepal, Milton Friedman, conhecido como um economista ultraliberal, desempenhou a mesma função após o golpe militar de Pinochet, em 1973 (BRESSERPEREIRA, 2011). Na guerra entre versões de modernização que representou a Guerra Fria (COOKE, MILLS e KELLEY, 2005), as propostas da Cepal não se alinharam a nenhum dos dois lados hegemônicos e, consequentemente, tornaram-se subalternizadas, mas deixaram profundas marcas na criação de organizações e instituições da região. As propostas da Cepal também atacavam a consolidada teoria ortodoxa das vantagens comparativas no comércio internacional, ao demonstrar que havia uma tendência de longo prazo à deterioração dos termos de troca (PREBISCH, 1949). Essa proposição ressaltava a assimetria no comércio internacional entre produtos industrializados, na maior parte produzidos no Norte e exportados para o Sul, e os produtos agrícolas e minerais, em sua grande maioria extraídos do Sul e exportados para o Norte (PREBISCH, 1949). Por essa razão, a Cepal sugeria o desenvolvimento da região pela industrialização por substituição de importações - ISI - e que esta deveria ser conduzida pela liderança do Estado. Na condição de desequilíbrio estrutural da região, a Cepal preconizava que o planejamento pelo Estado era fundamental para buscar o desenvolvimento hacía adentro (BIELSCHOWSKY, 1998), ou seja, o desenvolvimento para dentro do país por meio da industrialização e sob a liderança do Estado, e não por meio do incremento das exportações, como sugeria a teoria das vantagens comparativas, que implicava, também, abrir o país para as empresas e os produtos industriais produzidos, principalmente, no Norte.

Essas propostas defendidas pela Cepal deixam claro que outra perspectiva estava sendo proposta a partir de outro lócus de enunciação (MIGNOLO, 2011) e que pressupunha uma diferente relação entre organizações e desenvolvimento daquela proposta pelo conhecimento em EOR produzido no Norte. A lógica do Norte pressupunha que a grande empresa atuando livremente no mercado seria o principal motor da economia de um país, enquanto que o Estado estaria fora do escopo de análise (CHANDLER, 1962). Por outro lado, pela proposta da Cepal, o Estado teria papel central na condução do processo de desenvolvimento e caberia a este liderar a iniciativa privada. Portanto, seguiam outra lógica associada a um processo de desenvolvimento: podemos argumentar que, nessa lógica, o gestor do Estado poderia ser tanto ou mais estrategista do que a "mão visível" (CHANDLER, 1977) do gestor na iniciativa privada. E, a partir dessa lógica, poderemos compreender que, enquanto Chandler (1962) afirmava que as grandes empresas representavam o motor do desenvolvimento dos EUA, Furtado (1966), por sua vez, enunciava que as mesmas grandes empresas americanas estavam impedindo o potencial de desenvolvimento das sociedades latino-americanas.

Não queremos com isso sugerir que as propostas feitas pela Cepal sejam isentas de críticas nem que representam um purismo do pensamento social da América Latina. Certamente, a crença da Cepal na capacidade do Estado de planejar e liderar os gestores privados contribuiu para a naturalização do discurso de desenvolvimento e para sua percepção de aparente neutralidade (IANNI, 1971). Também concordamos que a Cepal "ao invés de imaginar alternativas ao desenvolvimento, tenha procurado orquestrar uma proposta para dominá-lo" (WOLFE, 1997, p. 397). Não obstante, podemos reconhecer que a penetração das ideias da Cepal nos EUA "pelo menos destruiu o otimismo ingênuo sobre desenvolvimento professado pelos teóricos da modernização estadunidense" (CHIROT e HALL, 1982, p. 93). Em outras palavras, o que este artigo 
defende é que as proposições teóricas da Cepal representam um desafio ao conhecimento produzido no Norte e à correspondente imposição da ordem única neoliberal.

\section{A (Re)Formulação do Estruturalismo da Cepal em Tons Marxistas: "Um Espantalho Fácil de Destruir"?}

No final dos anos 1950 a Guerra Fria havia se expandido para a América Latina e atingiu um ponto de inflexão quando, em 1959, as tropas de Fidel Castro e Che Guevara conquistaram Cuba e "transformaram o imaginário político de muitos latino-americanos" (GROSFÓGUEL, 2002, p. 357). A ameaça do alastramento do comunismo pela região tornou-se um perigo iminente. Pode não ser coincidência o fato de que, apenas dois meses após o golpe em Cuba, os EUA assinaram com o governo brasileiro o convênio PBA-1, pelo qual seria financiada a expansão dos centros de ensino de administração no país (ver FISCHER, 1984; BARROS e CARRIERI, 2013). O acordo para a vinda de 16 professores americanos "visando à adoção de um programa unificado de ensino de administração pública e de empresas" (CAPES, 1958, p. 15) havia sido assinado no final do ano anterior. Esse acordo foi assinado entre o Ministério da Educação, o Departamento de Administração do Serviço Público (DASP), a FGV, o Programa Ponto IV, dos EUA, e as universidades de Minas Gerais, da Bahia e do Rio Grande do Sul (CAPES, 1958). Cinco meses parece um tempo curto para a finalização de um acordo dessa envergadura e com tantas partes envolvidas. Portanto, o golpe em Cuba parece ter, pelo menos, acelerado o processo decisório e de implantação do programa.

Nesse momento, a Cepal passava por uma forte autocrítica, dado que o modelo de substituição de importações não se mostrava efetivo no que se referia à distribuição de renda. Muito influenciada pelos governos com tendências de esquerda que haviam tomado o poder na região, a Cepal passara a sugerir uma agenda de reformas, como a agrária, que feria interesses estabelecidos, não somente do Norte, mas, também, locais, além de, já no final dos anos 1950, propor uma aliança regional por meio da Associação Latino Americana de Livre Comércio (ALALC) (BIELSCHOWSKY, 1998). Parece que essas ideias geradas a partir do "exterior da parte interior" tornaram-se muito exteriores para que pudessem ser aceitas pelos governos da região e, consequentemente, a efetividade da influência da Cepal na região entra em declínio (LOVE, 2005). Isso se dá concomitantemente à criação da Aliança para o Progresso de JF Kennedy (196163) - para a qual o próprio Prebisch teria sido convidado - que encampa a agenda da Cepal (POLLOCK, KERNER e LOVE, 2001), em uma clara tentativa socialdemocrata de conter o potencial avanço do comunismo na região. A Aliança para o Progresso será coordenada pela OEA e, dez anos após a tentativa frustrada de fusão desta com a Cepal, liderada pelos EUA, finalmente atingirá o objetivo dos EUA de obstruir a Cepal como agente indutor de políticas de desenvolvimento, a partir de outra perspectiva, na América Latina.

Como consequência da radicalização dos movimentos de esquerda que se espalharam pela região e apoiados por instituições estadunidenses (ver, por exemplo, para o caso brasileiro, BLACK, 1977), uma sequência de golpes militares de direita toma o poder através da América Latina: Brasil, 1964; Argentina, 1966; Uruguai, 1967; e Chile, 1973. O modelo de conhecimento em EOR que deveria prevalecer tornou-se ainda mais claro no momento em que as ditaduras fecharam e desbarataram as instituições que pregavam outro pensamento: no Brasil, o Iseb foi fechado, em uma das primeiras medidas do novo governo, e um inquérito foi aberto para avaliar as "tendências comunistas" da maioria de seus membros (ABREU, 2005); no Chile, o mesmo aconteceu com o Centro de Estudos Socioeconômicos (CESO) da Universidade do Chile, que tinha como diretor o brasileiro Theotonio dos Santos, que foi exilado no primeiro dia do golpe, mas que permaneceu por seis meses em Santiago asilado na embaixada do Panamá até que conseguisse um salvo-conduto para deixar o país. O escritório da Cepal em Santiago foi poupado, apesar de ter sofrido um cerco por um curto período, o que pode sugerir que, de fato, esta representava "o externo gerado a partir do interno" (MIGNOLO e TLOSTANOVA, 2006).

A Cepal já passava por autocrítica desde os princípios dos anos 1960, quando, em 1963, seu líder praticamente desde a fundação, Prebisch, afasta-se para assumir uma posição na Conferência das Nações Unidas para Desenvolvimento e Comércio (UNCTAD) (DOSMAN, 2011). Em face da sequência de golpes 
militares e das manifestações de colonialidade epistêmica contra o conhecimento da Cepal discutidas, não deveria ser surpresa que as intervenções do estruturalismo da Cepal nas economias locais passassem a mostrar sinais de exaustão (LOVE, 2005). Dessa maneira, o corpo de críticas externas à Cepal cresce e vê-se impulsionado pela concentração em Santiago de diversos pensadores de esquerda que haviam sido expulsos de seus respectivos países após os golpes militares, o que propicia o início da discussão dos estudos da dependência sob uma perspectiva marxista (FRANK, 1966; SANTOS, 1970). Essa perspectiva vinha sendo introduzida nas ciências sociais da América Latina desde o princípio dos anos 1960.

O golpe militar no Brasil, em março de 1964, cassou os direitos políticos de Furtado e de muitos outros intelectuais, acadêmicos e políticos, que foram obrigados a deixar o país. Os anos 1960 marcam o período em que as principais fundações estadunidenses - Ford, Rockfeller e Carnegie - intensificaram o financiamento de pesquisadores da América Latina (PARMAR, 2002; ALCADIPANI, 2010), ao mesmo tempo que o projeto "Camelot", engendrado no Norte para "ordenar" a produção de conhecimento em ciências sociais no Sul, é colocado em marcha (ver, para o caso chileno, NAVARRO e QUESADA, 2010). Entendemos que esse processo, que representa como funciona a lógica da colonialidade (MIGNOLO, 2011), levou ao enfraquecimento da posição da Cepal, ao mesmo tempo que os estudos da dependência viriam a ser reformulados como a teoria marxista/neomarxista da dependência, sempre seguindo uma lógica de pensamento da (e a partir da) América Latina.

O estruturalismo foi originalmente formulado com base na historiografia político-econômica dos países latino-americanos, em sua grande maioria por pesquisadores latinos (BEIGEL, 2010), isto é, a partir do lócus de enunciação do Sul, e com o objetivo de implementar políticas de desenvolvimento que visavam a combater seu atraso, que era parcialmente atribuído aos países do Norte. Posteriormente, foi reformulado sob diferentes matizes marxistas como a teoria da dependência (BRESSER-PEREIRA, 2011), mas isso já se deu em um momento no qual seus principais formuladores já se encontravam, em sua grande maioria, exilados e, portanto, afastados das práticas locais e alijados de sua capacidade efetiva de intervenção na realidade.

As novas ditaduras militares, apoiados pelo Norte contra a expansão do comunismo, descartaram as formulações marxistas que previam uma revolução socialista para romper o ciclo vicioso representado pelo subdesenvolvimento capitalista ao qual estaria fadada a região, com a exceção do Peru, por um curto período (SANTOS, 2000). Esse processo fez com que a TD fosse excluída da produção de conhecimento local e eliminada de sua capacidade de intervenção na realidade, forçando-a a se encerrar em um debate acadêmico em "discussões abstratas centradas em dirimir se a teoria da dependência era compatível com os textos de Marx, antes que estabelecer se era compatível, ou não, com a realidade histórica concreta que pretendia explicar" (BEIGEL, 2010, p. 136). O golpe militar de Pinochet no Chile em 1973, onde a Cepal (ainda) está localizada, eliminou as possibilidades dela seguir propondo conhecimento "externo gerado a partir do interno", ou seja, o interno acabou por (re)encobrir o externo. A implementação após o golpe das reformas neoliberais no Chile (BRESSER-PEREIRA, 2011), não deixou margem a dúvidas sobre qual modelo deveria prevalecer e, assim, a lógica da colonialidade seguiu operando.

Estudos da Dependência, Teoria Marxista da Dependência e as Possibilidades de Diálogo em Estudos Organizacionais

Como informamos na introdução deste artigo, entendemos que estudos da dependência englobam tanto o conhecimento produzido pela Cepal e por Furtado como o que viria posteriormente a ser reconhecido como "teoria marxista da dependência". Portanto, este artigo sugere que estudos da dependência estão firmemente imbricados na realidade socioeconômica da América Latina. Nesta seção discutimos as diferentes correntes dentro dos estudos da dependência e analisamos as possibilidades de diálogo com os estudos organizacionais. 
Os acadêmicos geralmente diferem no modo como classificam as diferentes correntes dos estudos da dependência e parece haver um consenso que não se deveria falar que haja uma só corrente (BEIGEL, 2010; BRESSER-PEREIRA, 2011; CHIROT e HALL, 1982; GROSFÓGUEL, 2002; KAY, 1991; LOVE, 1990; 2005; PALMA, 1978; VERNENGO, 2006; WOLFE, 1997). Neste artigo, optamos por seguir a análise de Bresser-Pereira (2011), que propõe uma divisão em três grupos: o considerado mais radical e de tendência marxista, que propunha o socialismo como a única solução possível para o subdesenvolvimento, cujos principais autores são os brasileiros Theotonio dos Santos, Ruy Mauro Marini e Vania Bambirra e o germano-americano André Gunder Frank; a dependência associada, liderada pelo brasileiro Fernando Henrique Cardoso e pelo chileno Enzo Faletto; e os "revisionistas" liderados por Celso Furtado e pelo chileno Osvaldo Sunkel. As duas últimas correntes propunham uma saída para o subdesenvolvimento dentro do capitalismo (LOVE, 2005).

Também há divergências entre os pesquisadores sobre quem seria o verdadeiro progenitor da TD. Alguns reconhecem Prebisch como esse autor (CHIROT e HALL, 1982), enquanto outros reconhecem Frank (1966) como o mais importante autor e fundador da TD (KAY, 1991; PALMA, 1978), apesar de sua curta exposição (1968-73) ao ambiente chileno, que se tornou o grande berço para a formulação dos principais pressupostos teóricos (BEIGEL, 2010). Devemos lembrar que, entre o golpe no Brasil (1964) e o golpe no Chile (1973), Santiago tornou-se o grande refúgio da América Latina para onde acorriam os exilados (BEIGEL, 2010). Contrariamente ao reconhecimento concedido por acadêmicos a Frank, alguns críticos afirmam que ele produzia "citações extensivas de várias fontes [...] que tornava difícil discernir se ele de fato tinha algo a acrescentar" (WOLFE, 1997, p. 394).

O que ficou registrado na literatura produzida em inglês foi um longo debate entre Cardoso e Frank. Cardoso (1977a, p. 8-9), quando se referiu às contribuições de Frank e outros autores estadunidenses da TD, afirmou que "a corrente neomarxista norte-americana nada acrescentou à perspectiva crítica da América Latina de antes dos anos 1960", e acusou Frank de fazer simplificações na TD que a transformaram em um "espantalho fácil de destruir" (CARDOSO, 1977a, p. 15). Frank (1977), por sua vez, considerava ingênua a posição assumida por Cardoso de que a burguesia conduziria o processo de desenvolvimento.

Os pesquisadores também divergem sobre as origens da TD: "apesar de o estruturalismo ser reconhecido como o progenitor, o marxismo é usualmente visto, implícita ou explicitamente, como a tradição primária da qual surgiu a dependência" (LOVE, 1990, p. 143). Talvez isso se deva ao fato de que "uma proveniência dupla é convenientemente atribuída à dependência, dando à doutrina um pedigree combinado norte e sulamericano" (WOLFE, 1997, p. 393). Em outras palavras, o que queremos afirmar é que a dependência tem origem no estruturalismo da Cepal e foi orquestrada por pesquisadores da (e para) a América Latina.

Todavia, independente de quantas correntes teve, de quem é considerado seu fundador e de em qual hemisfério teria sido gerada a teoria, o fato é que a dependência em suas variadas nuances enfrentou sistematicamente a colonialidade epistêmica (IBARRA-COLADO, 2006) imposta pela Norte, desde suas origens estruturalistas no momento seguinte ao manifesto de Havana, até sua reformulação com tendências marxistas. Podemos afirmar que a combinação da colonialidade epistêmica imposta pelo Norte, com as perseguições políticas praticadas pelos governos do Sul, implicou não só o nível da produção e disseminação de conhecimento, mas, também, impingiu restrições físicas e psicológicas a muitos dos teóricos do Sul envolvidos com os estudos da dependência. $\mathrm{Na}$ verdade, a maior parte dos autores mencionados se viu forçada a uma diáspora em seguida ao golpe militar no Brasil: Cardoso, Santos, Marini e Bambirra foram para o Chile, onde Frank depois se juntou a eles, enquanto que Furtado foi primeiro, por um ano, para os EUA e depois para a França (SANTOS, 2000; FURTADO, 1974). Após o golpe do Chile, que ocorreu no dia 11 de setembro de 1973, todos que lá estavam foram forçados a um segundo exílio, desta feita para o México, com a exceção de Frank e Cardoso. Frank havia escapado para seu país natal, a Alemanha, às vésperas do golpe chileno, enquanto Cardoso havia retornado ao Brasil no final dos anos 1960 beneficiado por um habeas corpus (CARDOSO, 2012).

Devemos reconhecer as dificuldades materiais e as pressões psicológicas que o exílio pode impor a quem deve produzir conhecimento. Os relatos desses autores falam da crueldade e da violência que representa o 
exílio (ver, por exemplo, CARDOSO, 2012). Além disso, estamos falando de um tempo no qual a internet não existia para facilitar a circulação do conhecimento. Até hoje, a maior parte da produção de Theotonio dos Santos, Marini e Bambirra está disponível somente em espanhol, além de muita coisa ter se perdido como produção mimeografada e circulada entre os pares (BEIGEL, 2010). Por exemplo, as principais obras de Bambirra (2012) e Marini (2012) foram publicadas em português somente quarenta anos após o original em espanhol.

Com os golpes militares se sucedendo na América Latina e os principais autores da TMD sendo forçados à clandestinidade e exílios em sequência, tanto sua capacidade de formulação quanto de atuação sobre a realidade se viram prejudicadas (MARTINS, 2011). Será no Chile, de Allende, quando Theotonio dos Santos detinha uma chefia de departamento no CESO que os autores da TMD chegaram a participar de formulações de política governamental (SANTOS, 2009). Contudo, o tempo de atuação curto foi interrompido pelo golpe do general Pinochet. Theotonio, que foi cassado pelo golpe, conseguiu que a embaixada do Panamá considerasse sua própria casa uma extensão da mesma, e permaneceu aí por seis meses até conseguir um salvo-conduto do novo governo para deixar o Chile em direção ao México (SANTOS, 2009).

Infelizmente, no Brasil, "o silêncio imposto pela ditadura militar e, posteriormente, pelo discurso monológico do mercado total colocaram a tradição crítica brasileira no esquecimento" (MISOCZKY e FLORES, 2009, p. 522). Portanto, entendemos que resgatar as contribuições da Cepal e dos demais teóricos da dependência é uma forma de resistir à colonialidade epistêmica que impõe conhecimento estrangeiro e abrir o espaço para debates no campo de EOR, e promover alternativas à ordem única neoliberal.

Resumindo as proposições apontadas neste ensaio pelos estudos da dependência promovidos pela Cepal, listamos a seguir as possibilidades de aproximação das contribuições da Cepal com EOR:

a) Questionamento da universalidade do conhecimento estrangeiro;

b) Construção de arcabouços teóricos baseados na investigação da realidade local;

c) Inserção do estudo da realidade local na long durée do capitalismo global;

d) Reconhecimento das assimetrias entre centro e periferia, não somente no caso da produção de bens como sugerido pela Cepal, mas, também, na produção de conhecimento que gera uma dependência acadêmica (ALATAS, 2003);

e) Reconhecimento do papel do Estado e das empresas comandadas pelo Estado como uma normalidade do fenômeno organizacional;

f) Reconhecimento do papel do estrategista do Estado como sendo tanto ou mais importante do que o estrategista da iniciativa privada;

g) Questionamento da legitimidade da capacidade do mercado livre de promover a otimização dos recursos da sociedade, negando a capacidade da "mão invisível" de promover a autorregulação dos mercados; e, consequentemente,

h) Questionamento da centralidade do mercado.

Naturalmente, grande parte dessas proposições já vem sendo discutida em EOR. Entendemos que essas proposições possibilitam reconhecer a produção de conhecimento local "não como expressões de exotismo, mas como formas críticas relevantes de conhecimento produzido e vivido a partir da perspectiva de diferentes histórias e tradições" (MISOCZKY, 2011, p. 360). Faz-se, portanto, necessário o reconhecimento das diferentes correntes dos estudos da dependência como forma de "girar a geografia do conhecimento" 
(MIGNOLO, 2011) e promover a investigação da realidade social da (e para a) América Latina. Faz-se necessário, também, reconhecer que os estudos da dependência em suas diferentes correntes caracterizam a long durée do pensamento social crítico latino-americano e que, assim, podem contribuir para ampliar o espaço de diálogo em EOR e escapar da lógica única do pensamento neoliberal.

\section{Considerações Finais}

Neste artigo, apresentamos uma perspectiva histórica crítica descolonial (MIGNOLO, 2000; 2007; 2011), com o objetivo de trazer à superfície as contribuições dos estudos da dependência produzidos pela Cepal como alternativa ao pensamento neoliberal. Este artigo sugere que essa contribuição teórica do pensamento social crítico da América Latina pode ser mais bem apreciado se nos desvencilharmos da colonialidade epistêmica que procura apresentar a dependência como uma corrente teórica meramente economicista ou como somente atrelada a uma tradição marxista. É necessário o reconhecimento das diferentes teorizações que compõem os estudos da dependência e as contribuições que cada uma pode trazer para ampliar o debate em EOR e promover alternativas à ordem única neoliberal.

Os diversos autores latino-americanos que compõem os estudos da dependência procuraram analisar a realidade da região a partir de premissas que iam de encontro às teorias tradicionais produzidas no Norte. Mais que isso, a partir da práxis sociopolítica da região fizeram uma revisão crítica da tradição eurocêntrica e que tinha por objetivo a transformação da realidade latino-americana. Argumentamos que descolonizar o conhecimento produzido pelas diferentes correntes dos estudos da dependência é uma maneira de fomentar respostas críticas da América Latina dentro da área de estudos organizacionais em uma era demarcada pelo declínio do conhecimento euroamericano, mas que resiste em manter sua preponderância por meio do neocolonialismo.

Como proposto por Furtado (1974), o Estado deve atuar em favor da sociedade, e não em favor do mercado. Sob influência desse pensamento diferentes organizações e instituições foram criadas sob a tutela do Estado, ou incentivadas por este. Tais organizações, que caracterizam o Brasil ainda hoje, poderiam ser investigadas pelos pesquisadores em EOR por meio das lentes da TD. Sobretudo as questões de poder e política e assimetria entre regiões elaboradas pelas diferentes correntes dos estudos da dependência deveriam ser apreciadas pelos pesquisadores em organizações, junto com a estrutura de análise histórico-estrutural proposta, principalmente, por Furtado e pela Cepal. Assim, diante das peculiaridades dessas importantes organizações nacionais que, aparentemente, distanciam-se dos modelos das grandes corporações privadas norte-americanas, estudos sobre a tomada de decisão, racionalidade econômica e política, ingerências de diversas naturezas e particularidades do controle hierárquico seriam bem-vindos.

Finalmente, esperamos que este estudo e a perspectiva aqui apresentada possam estimular outros pesquisadores a aplicar a historiografia em gestão e estudos organizacionais a partir de "um pensamento crítico das margens do sul" (MIGNOLO e TLOSTANOVA, 2006). Devemos buscar girar a geografia do raciocínio (MIGNOLO, 2011), para revelar outros conhecimentos, tanto do Sul como do Norte, que porventura tenham sido subalternizados pela colonialidade epistêmica. A partir do lócus de enunciação da América Latina, devemos estar cientes de que "não basta mudar o conteúdo da conversa, é essencial que se mudem os termos da conversação [...] isto quer dizer, questionar as premissas que sustentam o lócus de enunciação" (MIGNOLO, 2009, p. 4; grifo do autor). Para tanto, não devemos nos contentar em aderir a uma suposta "virada histórica" conforme proposto por autores do Norte, faz-se também necessária uma "virada geográfica", que já se encontrava presente nas formulações iniciais dos estudos da dependência como proposto pela Cepal.

Como sugere o título de um dos artigos de Frank (1977), "A dependência está morta, vida longa à dependência!". Que a dependência seja uma das formas de fazer girar a geografia do conhecimento (MIGNOLO, 2011), para promover conhecimentos do Sul que possam informar não somente as realidades locais, mas, também, as do Norte, em busca de um campo de estudos organizacionais que seja pluriversal e um mundo multipolar. 


\section{Referências}

ABREU, A. A. A ação política dos intelectuais do Iseb. In: TOLEDO, C. N. (Org.). Intelectuais e política no Brasil: a experiência do Iseb. Rio de Janeiro: Revan, 2005. 97-118 p.

ALATAS, S. Academic dependency and the global division of labour in the social sciences. Current Sociology, v. 51, n. 6, p. 599-613, 2003.

ALCADIPANI, R. From Latin America to the world: notes on the (possible) Latin American management styles. In: GUEDES, A.; FARIA, A. (Eds.). International management and international relations: a critical perspective from Latin America. New York: Routledge, 2010. 136-158 p.

ALCADIPANI, R.; BERTERO, C. Guerra Fria e ensino do management no Brasil: o caso da FGV-EAESP. Revista de Administração de Empresas, v. 52, n. 3, p. 284-299, 2012.

ALCADIPANI, R.; CALDAS, M. Americanizing Brazilian management. Critical Perspectives on International Business, v. 8, n. 1, p. 37-55, 2012.

ALCADIPANI, R. et al. Southern voices in management and organization knowledge. Organization, v. 19, n. 2, p. 131-143, 2012.

ARQUIVOS CELSO FURTADO. O Nordeste e a saga da Sudene: 1958-1964. Rio de Janeiro: Contraponto, 2009. v. 3 .

BALleStRIN, L. América Latina e o giro decolonial. Revista Brasileira de Ciência Política, n. 11, p. 89-117, 2013.

BAMBIRRA, V. O capitalismo dependente latino-americano. Florianópolis: Insular, 2012.

BARROS, A.; CARRIERI, A. Ensino superior em Administração entre os anos 1940 e 1950: uma discussão a partir dos acordos de cooperação Brasil-Estados Unidos. Cadernos EBAPE.BR, v. 11, n. 2, p. 256-273, 2013.

BEIGEL, F. Vida, muerte y resurrección de las "teorías de la dependencia”. In: BEIGEL, F. et al. Crítica y teoría en el pensamiento social latinoamericano. Buenos Aires: CLACSO, 2006. 287-326 p.

BEIGEL, F. La teoria de la dependencia en su laboratorio. In: BEIGEL, F. (Org.). Autonomía y dependencia académica: universidad e investigación científica en un circuito periférico - Chile y Argentina (1950-1980). Buenos Aires: Biblos, 2010. 129-144 p.

BNDE. Exposição sobre o programa de reaparelhamento econômico: exercício de 1955. Rio de Janeiro: BNDE, 1956.

BNDE. Exposição sobre o programa de reaparelhamento econômico: exercício de 1956. Rio de Janeiro: BNDE, 1957.

BIANCHI, A. For different audiences, different arguments: economic rhetoric at the beginning of the Latin American School. Journal of the History of Economic Thought, v. 24, n. 3, p. 291-305, 2002.

BIELSCHOWSKY, R. Pensamento econômico brasileiro: o ciclo ideológico do desenvolvimento. Rio de Janeiro: Contraponto, 1987.

BIELSCHOWSKY, R. (Org.). Cinquenta anos de pensamento na Cepal. Rio de Janeiro: Record, 1998.

BLACK, J. United States penetration of Brazil. Philadelphia, PA: University of Pennsylvania Press, 1977.

BOOTH, C.; ROWLINSON, M. Management and organizational history: prospects. Management \& Organizational History, v. 1, n. 1, p. 5-30, 2006. 
BRESSER-PEREIRA, L. From the national-bourgeoisie to the national dependency interpretation of Latin America.

Latin American Perspectives, v. 38, n. 3, p. 40-58, 2011.

CAMPANHA DE APERFEIÇOAMENTO DE PESSOAL DE ENSINO SUPERIOR - CAPES. Boletim Capes, n. 45 , 1956.

CAPES. Boletim Capes, n. 72, 1958.

CAPES. Boletim Capes, n. 90, 1960.

CARDOSO, F. H. The consumption of dependency theory in the United States. Latin American Research Review, v. 12, n. 3, p. 7-24, 1977a.

CARDOSO, F. H. The originality of a copy: CEPAL and the idea of development. CEPAL Review. 2. Half, 1977b. $7-$ $42 \mathrm{p}$.

CARDOSO, F. H. A soma e o resto: um olhar sobre a vida aos 80 anos. Rio de Janeiro: Civilização Brasileira, 2012.

CASTRO-GÓMEZ, S. Decolonizar la universidad: la hybris del punto certo y el diálogo de saberes. In: CASTROGÓMEZ, S.; GROSFÓGUEL, R. (Eds.). El giro decolonial: reflexiones para una diversidad epistémica más allá del capitalismo global. [s.1]: [s.n], 2007. 79-92 p.

CHANDLER, A. D. Strategy and structure: chapters in the history of the American industrial enterprise. Cambridge, MA: Massachusetts Institute of Technology Press, 1962.

CHANDLER, A. D. The visible hand: the managerial revolution in American business. Cambridge, MA: Harvard University Press, 1977.

CHIROT, D.; HALL, T. World-system theory. Annual Review of Sociology, v. 8, p. 81-106, 1982.

CLARK, P.; ROWLINSON, M. The treatment of history in organization studies: toward an "historic turn"? Business History, v. 46, p. 331-352, 2004.

COOKE, B.; MILLS, A.; KELLEY, E. Situating Maslow in Cold War America: a recontextualizaiton of management theory. Group and Organization Management, v. 30, n. 2, p. 129-152, 2005.

DAR, S.; COOKE, B (Eds.). The new development management. London: Zed, 2008. 1-17 p.

DOSMAN, E. Raúl Prebisch (1901-1986): a construção da América Latina e do Terceiro Mundo. Rio de Janeiro: Contraponto, 2011.

DUSSEL, E. 1492: o encobrimento do outro - a origem do mito da modernidade. Petrópolis, RJ: Vozes, 1993.

ESCOBAR, A. Power and visibility: development and the invention and management of the third world. Cultural Anthropology, v. 3, n. 4, p. 428-443, 1988

ESCOBAR, A. Imagining a post-development era? Critical thought, development and social movements. Third World and Post-Colonial Issues, v. 31-32, p. 20-56, 1992.

ESCOBAR, A. Worlds and knowledge otherwise: the Latin American modernity/coloniality research program. Cultural Studies, v. 21, n. 2-3, p. 179-210, 2007.

FARIA, A.; GUEDES, A. Globalization and International Management: In search of an Interdisciplinary Approach. Brazilian Administration Review, v. 4, n. 2, p. 20-39, 2007.

FISCHER, T. O ensino de administração pública no Brasil, os ideais de desenvolvimento e as dimensões da racionalidade. Tese (Doutorado em Administração) - Faculdade de Economia e Administração, Universidade de São Paulo, São Paulo, 1984. 
FRANK, A. G. The development of underdevelopment. Monthly Review, v. 18, n. 4, p. 17-31, 1966.

FRANK, A. G. Dependence is dead, long live dependence and the class struggle: an answer to critics. World Development, v. 5, n. 4, p. 355-370, 1977.

FURTADO, C. Desenvolvimento e subdesenvolvimento. Rio de Janeiro: Fundo de Cultura, 1961.

FURTADO, C. U. S. hegemony and the future of Latin America. The World Today, v. 22, n. 9, p. 375-385, 1966.

FURTADO, C. O mito do desenvolvimento econômico. Rio de Janeiro: Paz e Terra, 1974.

FURTADO, C. O capitalismo global. São Paulo: Paz e Terra, 1998.

FURTADO, C. Centro Internacional Celso Furtado. Memórias do Desenvolvimento, v. 3, n. 3, p. 101-122, 2009.

GRANT, J.; MILLS, A. The quiet Americans: formative context, the Academy of Management Leadership, and the management textbook, 1936-1960. Management \& Organizational History, v. 1, n. 2, p. 201-224, 2006.

GROSFÓGUEL, R. Developmentalism, modernity and dependency: theory in Latin America. Neplanta, v. 1, n. 2, p. 347-374, 2002.

GROSFÓGUEL, R. Decolonizing post-colonial studies and paradigms of political-economy: transmodernity, decolonial thinking, and global coloniality. Transmodernity, v. 1, n. 1, p. 1-18, 2011.

IANNI, O. Estado e planejamento econômico no Brasil (1930-1970). Rio de Janeiro: Civilização Brasileira, 1971.

IBARRA-COLADO, E. Organization studies and epistemic coloniality in Latin America: thinking otherness from the margins. Organization, v. 13, n. 4, p. 489-508, 2006.

IBARRA-COLADO, E. Is there any future for critical management studies in Latin America? Moving from epistemic coloniality to 'trans-discipline'. Organization, v. 15, n. 6, p. 932-935, 2008.

JACQUES, R. Manufacturing the employee: management knowledge from the $19^{\text {th }}$ to $21^{\text {st }}$ centuries. London: Sage, 1996.

JACQUES, R. History, historiography and organization studies: the challenge and the potential. Management \& Organizational History, v. 1, n. 1, p. 31-49, 2006.

KAY, C. Reflections on the Latin American Contribution to Development Theory. Development and Change, v. 22 , n. 1, p. 31-68, 1991.

KELlEY, E.; MILlS, A.; COOKE, B. Management as a Cold War phenomenon? Human Relations, v. 59, n. 5, p. 603-610, 2006.

KUBITSCHEK, J. Diretrizes gerais do plano nacional de desenvolvimento. Belo Horizonte: Oscar Nicolai, 1955.

LANDAU, O. Cold War political culture and the return of system rationality. Human Relations, v. 59, n. 5, p. 637$663,2006$.

LOVE, J. The origins of dependency analysis. Journal of Latin American Studies, v. 22, n. 1, p. 143-168, 1990.

LOVE, J. The rise and decline of economic structuralism in Latin America. Latin American Research Review, v. 40, n. 3, p. 100-125, 2005.

MARINI, R. Subdesenvolvimento e revolução. Florianópolis: Insular, 2012.

MARTINS, C. Globalização, dependência e neoliberalismo na América Latina. São Paulo: Boitempo, 2011. 
MCLAREN, P. James Burnham. The Managerial Revolution, and the Development of Management Theory in PostWar America. Management \& Organizational History, v. 6, n. 4, p. 411-23, 2011.

MCLAREN, P.; MILLS, A. A product of "his" time? Exploring the construct of the ideal manager in the Cold War era. Journal of Management History, v. 14, n. 4, p. 386-403, 2008.

MIGNOLO, W. Local histories/global designs. Princeton, NJ: Princeton Press, 2000.

MIGNOLO, W. Delinking: the rhetoric of modernity, the logic of coloniality and the grammar of de-coloniality. Cultural Studies, v. 21, n. 2-3, p. 449-514, 2007.

MIGNOLO, W. Epistemic disobedience, independent thought and de-colonial freedom. Theory, Culture \& Society, v. 26, n. 7-8, p. 1-23, 2009.

MIGNOLO, W. The darker side of Western modernity: global futures, decolonial options. London: Duke University Press, 2011.

MIGNOLO, W.; TLOSTANOVA, M. Theorizing from the borders: shifting to geo- and body-politics of knowledge. European Journal of Social Theory, v. 9, n. 2, p. 205-221, 2006.

MISOCZKY, M. C. World visions in dispute in contemporary Latin America: development x harmonic life. Organization, v. 18, n. 3, p. 345-363, 2011.

MISOCZKY, M. C.; FLORES, R. A práxis-crítica na tradição do pensamento social brasileiro. Cadernos EBAPE.BR, v. 7, n. 3, p. 517-524, 2009.

MURPHY, J.; ZHU, J. Neo-colonialism in the academy? Anglo-American domination in management journals. Organization, v. 19, n. 4, p. 915-927, 2012.

NAVARRO, J. J.; QUESADA, F. El proyecto Camelot (1964-1965). La dependencia académica, entre el escándalo y el mito. In: BEIGEL, F. (Org.). Autonomía y dependencia académica: universidad e investigación científica em un circuito periférico - Chile y Argentina (1950-1980). Buenos Aires: Biblos, 2010. 145-168 p.

PALMA, G. Dependency: a Formal Theory of Underdevelopment or a Methodology for the Analysis of Concrete Situations of Underdevelopment? World Development, v. 6, p. 881-924, 1978.

PARMAR, I. American foundations and the development of international knowledge networks. Global Networks, v. 2 , n. 1, p. 13-30, 2002.

POLLOCK, D.; KERNER, D.; LOVE, J. Raúl Presbisch on ECLAC's achievements and deficiencies: an unpublished interview. Cepal Review, n. 75, p. 9-22, 2001.

PREBISCH, R. El desarrollo económico de la América Latina y sus principales problemas: E/CN.12/89. Santiago: [s.n], 1949.

QUIJANO, A. Modernidad, colonialidad y América Latina. Neplanta, v. 1, n. 3, p. 533-580, 2000.

RAMOS, A. G. A redução sociológica. Rio de Janeiro: Iseb, 1958.

RODRIGUES, S.; CARRIERI, A. A tradição anglo-saxônica nos estudos organizacionais brasileiros. Revista de Administração Contemporânea, v. 5, n. edição especial, p. 81-102, 2001.

ROSA, A.; ALVES, M. Pode o conhecimento em gestão e organização falar português? Revista de Administração de Empresas, v. 51, n. 3, p. 255-264, 2011.

ROSTOW, W. The stages of economic growth: a non-communist manifesto. Cambridge: Cambridge University Press, 1960. 
ROWLINSON, M.; JACQUES, R.; BOOTH, C. Critical management and organizational history. In: ALVESSON, M.; BRIDGMAN, T.; WILLMOTT, H. (Org.). The Oxford handbook of critical management studies. Oxford: Oxford University Press, 2009. 286-303 p.

SANTANA, J. C. Memória institucional da Cepal/Ilpes nos seus 30 anos de contribuição permanente no Brasil (setembro de 1960 a setembro de 1990). Santiago: Cepal, 1990.

SANTOS, T. The structure of dependence. The American Economic Review, p. 231-236, 1970.

SANTOS, T. A teoria da dependência: balanço e perspectivas. Rio de Janeiro: Civilização Brasileira, 2000.

SANTOS, T. Bendita crisis! Socialismo y democracia em el Chile de Allende. 2009. Disponível em: <https://docs.google.com/document/d/1iVM-ehIUMpIJH6njwwDg8dBNAO4poBl_GdEFKvsPh_Q/edit?pli=1>. Acesso em: 17 out. 2014.

SARAIVA, E.; CARRIERI, A. Citações e não citações na produção acadêmica no Brasil: uma reflexão crítica. Revista de Administração USP, v. 44, n. 2, p. 158-166, 2009.

SODRÉ, W. A verdade sobre o Iseb. Rio de Janeiro: Avenir, 1978.

SPECTOR, B. The Harvard Business Review goes to war. Management \& Organizational History, v. 1, n. 3, p. $273-$ 295, 2006.

SUNKEL, O. Big business and “dependencia”. Foreign Affairs, v. 50, p. 517-531, 1972.

TRUMAN, H. Inaugural address. 20 jan. 1949. Disponível em: <www.bartleby.com/124/pres53.html>. Acesso em: 10 out. 2012.

VALENZUELA, J. S.; VALENZUELA, A. Modernization and dependency: alternative perspectives in the study of Latin American underdevelopment. Comparative Politics, v. 10, n. 4, p. 535-557, 1978.

VERNENGO, M. Technology, finance, and dependency: Latin American radical political economy in retrospect. Review of Radical Political Economics, v. 38, n. 4, p. 551-568, 2006.

WANDERLEY, S.; FARIA, A. The Chandler-Furtado case: a decolonial (re)framing of a North/South (dis)encounter. Management \& Organizational History, v.7, n. 3, p. 219-236, 2012.

WESTWOOD, R.; JACK, G. The US commercial-military-political complex and the emergence of international business and management studies. Critical Perspectives on International Business, v. 4, n. 4, p. 367-288, 2008.

WOLFE, P. History and imperialism: a century of theory, from Marx to postcolonialism. The American Historical Review, v. 102, n. 2, p. 388-420, 1997.

WAIANDT, C. A. O ensino dos estudos organizacionais nos cursos de pós-graduação stricto sensu em administração. (Tese doutorado em administração), Universidade Federal da Bahia, Salvador, 2009. 